\title{
How do Chinese High School Graduates Choose Their Majors: An Analysis Based on the Individual and Family Background
}

\author{
Xin-hong WANG ${ }^{1,{ }^{*}}$ and Wen-hui $\mathrm{LI}^{1}$ \\ ${ }^{1}$ School of Public Policy and Administration, Xi'an Jiaotong University, Xi'an, China \\ ${ }^{*}$ Corresponding author: email: xhwang@mail.xjtu.edu.cn
}

Keywords: Major choice, Chinese students, College entrance examination achievement, Census register, Gender.

\begin{abstract}
Based on the freshmen enrollment information in a western university of China, this study explored the effects of individual background and family background on the major choice of higher school students in China. The study found that gender is an important factor influencing the choice of students in S\&T majors, male high school graduates prefer to choose S\&T majors. College entrance examination achievement also affects the choice of students, the higher the achievement, the greater the possibility of high school graduates to choose S\&T majors. Census register can also predict the choice of students in S\&T majors, urban students are more inclined to choose S\&T majors.
\end{abstract}

\section{Introduction}

The college entrance examination is one of the most important systems in China. This system influences the fate of most high school graduates. The choice majors and schools have immeasurable effects on their future life and career development. Some scholars have focused on the psychology and behavior of major choice among Chinese higher school students. Using the reverse research method, this paper analyzed the relevant data of freshmen in a western top university in China, and explored how gender, college entrance examination achievement and census register affected high school graduates' major choice.

\section{Literature Review}

Some scholars found that students' major choice was affected by personal factors, family factors, college factors and social factors [1]. Gender, academic achievement (personal academic ability), and family background are the most representative factors among personal factors and family factors.

\section{Gender and Major Choice}

Farley (2004) [2] pointed out that there were many scholars who had investigated the students' choice of college major: Polachek (1978) [3] studied the differences between male and female students in major choice first. He found that, controlling for other individual and family characteristics, gender had a significant effect on the choice of all major fields except social sciences and fine arts. Blakemore and Low (1984) [4] also found that females with higher expected fertility were more likely to choose majors that were less subject to obsolescence with significant time out of the workforce. Jacobs (1995) [5], Roksa (2005) [6], 
England and $\mathrm{Li}$ (2006) [7] stated that females tend to major in humanities and social science, while males tend to major in natural science and engineering.

There are also many Chinese scholars who studied the gender differences in students' major choice. Fang (1990) [8] investigated 1708 students from 9 universities in Xiamen and Fuzhou, and found that there were much more females gathering in humanities and social science and normal majors, but only a few females in science and engineering. Guo et al. (2007) [9] investigated more than 20000 students in China, and sifted the data of students with bachelor degree in S\&T to analyze, they found that males were significantly more than females in S\&T, especially in engineering majors. Wang et al. (2010) [10] investigated 3147 undergraduate students in China, and found that when entering university, engineering was the most expected major for male and female high school students, there was no difference between male and female students. But in the graduate, the rates of males increased while females not, and there was significant difference between males and females.

\section{Academic Achievement and Major Choice}

Some foreign scholars concerned the effect of students' study and scores of math and science on their major choice. Simpson (2001) [11] found that, in general, students who studied more math and science courses in high school were more likely to choose technical majors. In addition, the higher the students' math test scores, the greater the chance to choose technical majors. Song and Glick (2004) [12] studied 9202 American students' college major choice and found that students who got higher scores in mathematics in high school were not only more likely to enter the university, but also tend to choose majors which had higher earning potential. In addition, math test score in high vyschool is the most powerful predictor of their college major choice both for males and females. Olitsky (2009) [13] pointed out that the academic achievement of individuals played a very important role in their major choice, because some majors required a high level of academic preparation, that's why some specific majors appealed to individuals who had good academic preparation, for example, engineering and technological majors would often attract students who had better academic achievement in math and science.

Yang (2011) [14] extracted 1036 students who had just finished their college entrance examination fromLiaoning province to research, the results suggested that students' grades in high school had very little impact on their college major choice, because there were a lot of majors set up in different levels of colleges and universities. Zhang (2002) [15] pointed out that the current college entrance system in China is to admit the best examinees through the college entrance examination, so students' major choice depended on their academic achievement. Concluding scholars' viewpoints on students' college major choice in China, that is, college entrance examination achievement had little influence on students' college major choice if considering all the colleges and universities as a whole, because there are same majors in different levels of colleges and universities. But college entrance examination achievement would affect students' college major choice in a college or university.

\section{Family Background and Major Choice}

Domestic and foreign scholars have paid attention to the influence of family background on students' college major choice very early. Bourdieu and Passeron [16, 17] studied 211879 college students of 1961-1962 school year and counted their family social background, they found that students from adverse social class were limited more in their major choice. Rochat 
and Demeulemeester (2001) [18] thought that the risks that students faced were the important factors affecting their major choice, individuals faced at least two kinds of risks when they chose the school and major: the first one was the risk of academic competition that was the possibility to finish their school work, the second was the risk of employment competition that was the possibility to get high market returns after graduation, and students would consider the risk of academic competition while choosing the school and major. They found that students from low-income groups tend to choose majors such as pedagogy, humanities and arts of which the risk of academic competition was lower when controlling students' academic ability, though the market returns of these majors were lower, and students from high-income groups preferred to choose S\&T majors of which the market returns were higher. However, Ma (2009) [19] just got the opposite conclusion, he found that students from low family socioeconomic background tend to choose majors such as technology, life/health science and business rather than pedagogy and humanities because they could get higher returns after graduation in these major fields. Kim Weeden [20] summarized the education data in America and found that there were relations between the income level of students' parents and students' majors, students fromhigh-income families tend to choose liberal arts majors such as history, literature and performances, while students from low-income families preferred to choose S\&T majors with stronger practicability such as computer and physics for the sake of higher employment returns. And his statistics really showed that the average annual income of students in computer majors was $\$ 25000$ higher than those in humanities. The findings demonstrated the viewpoint again that the liberal arts majors were the majors for the rich, students from poor family situations were more inclined to choose S\&T majors with employment stability.

Chinese scholars Zhao and Qian (1999) [21] investigated 1395 college students' behavior of major choice and found that college students' major choice was mainly driven by the employment prospect of majors and their own study interests, and family had a little effect on college students' major choice. Wang and Gu (2005) [22] investigated the social stratification of students of all kinds of majors in 34 colleges and universities from several provinces in China. Their study found that there were differences among the entrance opportunities of students from different social stratifications, overall, more students studied in liberal arts, science, engineering, and management majors, and fewer students studied in economics, law, education and medical majors. And in liberal arts, sciences, engineering and management majors, students from high-income groups tend to choose those popular majors or majors with higher tuitions, and students from low-income groups tend to choose those basal majors or majors with lower tuitions. Dao and Ding (2008) [23] used the data from<CHUHEES-2005>and found that college students' major choice was influenced by their family background to a certain extent, but the directions of the impact were not consistent. Students whose fathers were well-educated and had better jobs tend to choose engineering, science and liberal arts majors rather than management and economics, on the contrary, students with better family economic conditions preferred liberal arts and management majors and their preference to engineering, science and economics was relatively stable. Cui (2012) [24] studied the relations between family background and students' major choice from the social capital, economic capital and cultural capital, and found that in an ideal state, the main factors students considered when choosing their majors were university rankings, majors, teachers' level, teaching quality, academic achievement and tuitions, while factors such as parents' occupation, the willingness of their parents and family economic income had a little 
influence on students' major choice. But Cui suggested that family factors affected students' behavior of major choice through other factors. Yang (2014) [25] extracted 2500 undergraduates from two public ordinary colleges in midwestern China, his study found that students from low-income families tend to choose social science, science, engineering and medical majors rather than economics, management and arts majors with high tuitions both for males and females, parents' occupation had a significant effect on students' major choice, father's occupation affected more on males, while mother's occupation affected more on females.

\section{Data and Methods}

\section{Data}

Data comes from the college entrance examination enrollment data of a "985" university in western China.

The university is a comprehensive university based on engineering, which has almost set up all kinds of S\&T majors and has a long history and great academic reputation in China. The economic, management, humanities and social science disciplines of the university also develop rapidly in recent years. The university recruits about 4000 undergraduates every year.

\section{Variable Measurement}

There were four core variables in this research:

Major choice. Categorical variable. The major choice was measured by the question, "Did the students choose S \&T majors?" , $0=$ No, $1=$ Yes.

Gender. Categorical variable, $0=$ female, $1=$ male.

Census register. Categorical variable, $0=$ rural , $1=$ urban.

College entrance examination achievement. Categorical variable. Because there were different standards of the score of college entrance examination in different provinces in China, the study used the net increase in the score of students' college entrance examination and the score of the college entrance examination of students' home province. Using 'net increase of college entrance examination score" to define students' college entrance examination achievement, $1=0 \sim 40$ points, $2=41 \sim 80$ points, $3=81 \sim 120$ points, $4=121$ points and more.

The descriptive information of variables was shown in table 1 .

Table 1. The descriptive information of variables

\begin{tabular}{|c|c|c|c|}
\hline Variables & The descriptive information & Frequency(percentage) & $\min / \max$ \\
\hline \multirow[t]{2}{*}{ Major choice } & $0=\mathrm{No}$ & $938(25.8 \%)$ & \multirow[t]{2}{*}{$0 / 1$} \\
\hline & $1=$ Yes & $2698(74.2 \%)$ & \\
\hline \multirow[t]{2}{*}{ Gender } & $0=$ female & $990(27.2 \%)$ & \multirow[t]{2}{*}{$0 / 1$} \\
\hline & $1=$ male & $2646(72.8 \%)$ & \\
\hline \multirow[t]{2}{*}{ Census register } & $0=$ rural & $1315(36.2 \%)$ & \multirow[t]{2}{*}{$0 / 1$} \\
\hline & $1=$ uran & $2321(63.8 \%)$ & \\
\hline \multirow{4}{*}{$\begin{array}{c}\text { College entrance } \\
\text { examination } \\
\text { achievement }\end{array}$} & $1=0 \sim 40$ points & $393(10.8 \%)$ & \multirow{4}{*}{$1 / 4$} \\
\hline & $2=41 \sim 80$ points & $1919(52.8 \%)$ & \\
\hline & $3=81 \sim 120$ points & $1174(32.3 \%)$ & \\
\hline & $4=121$ points and more & $150(4.1 \%)$ & \\
\hline
\end{tabular}




\section{Analysis Strategy}

In order to compare the high school students' choice of S\&T majors and the influence factors, this study divided the samples into two groups - the group of students who chose S\&T majors, and the other group of students who didn't choose S\&T majors. And crosstabs and chi square test were applied first to compare the gender, college entrance examination achievement and census register of these two groups.

Because the dependent variable was a category variable with two categories, so binary logistic regression model was constructed to do the further analysis. There were three models: the independent variable of model 1 was gender, the independent variables of model 2 were gender and college entrance examination achievement, and the independent variables of model 3 were gender, college entrance examination achievement and census register.

\section{The Results and Analysis}

\section{Descriptive}

The result of descriptive analysis was shown in table 2 . We found that there were significant differences in gender and college entrance examination achievement between two groups of students, but there was not a significant difference in census register. The rate of males who chose S\&T majors was $79.9 \%$, which was significantly higher than the rate of males who didn't choose S\&T majors (52.1\%), and the rate of females who chose S\&T majors was only $20.1 \%$, which was significantly lower than the rate of females who didn't choose S\&T majors $(47.9 \%)\left(x^{2}=271.788, \mathrm{p}<.001\right)$. The rate of students whose college entrance examination achievement was between 0 80 points who chose S\&T majors was 59.2\%, which was significantly lower than those who didn't choose S\&T majors (76.2\%), and the rate of students whose college entrance examination achievement was 81 points and more who chose S\&T majors was $40.9 \%$, which was significantly higher than those who didn't choose S\&T majors $(23.7 \%)\left(x^{2}=187.357, \mathrm{p}<.001\right)$.

Table 2. The result of crosstabs and chi square test

\begin{tabular}{|c|c|c|c|}
\hline & & Major choice(Yes) & Major choice(No) \\
\hline & & number/ratio & number/ratio \\
\hline \multirow[t]{3}{*}{ Gender } & male & $2157(79.9 \%)$ & $489(52.1 \%)$ \\
\hline & female & $541(20.1 \%)$ & $449(47.9 \%)$ \\
\hline & $\mathrm{Chi}^{2}$ test & \multicolumn{2}{|c|}{$\mathrm{Chi}^{2}=271.788^{*} * *$} \\
\hline \multirow{5}{*}{$\begin{array}{c}\text { College entrance } \\
\text { examination } \\
\text { achievement }\end{array}$} & $0 \sim 40$ points & $193(7.2 \%)$ & $200(21.3 \%)$ \\
\hline & $41 \sim 80$ points & $1404(52.0 \%)$ & $515(54.9 \%)$ \\
\hline & $81 \sim 120$ points & $970(36.0 \%)$ & $204(21.7 \%)$ \\
\hline & 121points and more & $131(4.9 \%)$ & $19(2.0 \%)$ \\
\hline & $\mathrm{Chi}^{2}$ test & \multicolumn{2}{|c|}{$\mathrm{Chi}^{2}=187.357 * * *$} \\
\hline \multirow[t]{3}{*}{ Census register } & urban & $1736(64.3 \%)$ & $585(62.4 \%)$ \\
\hline & rural & $962(35.7 \%)$ & $353(37.6 \%)$ \\
\hline & $\mathrm{Chi}^{2}$ test & \multicolumn{2}{|c|}{$\mathrm{Chi}^{2}=1.179$} \\
\hline
\end{tabular}

Note: $+\mathrm{p}<0.1, * \mathrm{p}<0.05, * * \mathrm{p}<0.01, * * * \mathrm{p}<0.001$

\section{Regression Analysis}

Table 3 showed the result of binary logistic regression analysis. In model 1, we found that gender predicted the major choice of high school graduates, males were more likely to choose S\&T majors than females $(1.298, \mathrm{p}<.001)$. 
In model 2, gender and college entrance examination achievement were added as independent variables, the direction and strength of the influence of gender on major choice reminded unchanged. Compared to students whose college entrance examination achievement was between 0 40 points, college entrance examination achievement could predict high school students' major choice, the higher the college entrance examination achievement, the greater the chance to choose S\&T majors.

Model 3 included gender, college entrance examination achievement and census register as independent variables, and the directions and strengths of influences of gender and college entrance examination achievement on major choice reminded unchanged. Census register could predict major choice, urban students were more likely to choose S\&T majors than rural students $(0.240, \mathrm{p}<0.01)$.

The Cox \& Snell $\mathrm{R}^{2}$ and Nagelkerke $\mathrm{R}^{2}$ of model 1 were 0.068 and 0.100 . The Cox \& Snell $\mathrm{R}^{2}$ and Nagelkerke $\mathrm{R}^{2}$ of model 2 were 0.107 and 0.157 , obviously the inclusion of college entrance examination achievement improved the model's explanatory power. The Cox $\&$ Snell $\mathrm{R}^{2}$ and Nagelkerke $\mathrm{R}^{2}$ of model 3 were 0.109 and 0.160 , we could say that after adding the independent variable of census register, the explanatory power of the model also increased. Therefore, the model 3 was the optimal model.

Table 3. The result of regression analysis

\begin{tabular}{|c|c|c|c|}
\hline Dependent variable: & Model 1 & Model 2 & Model 3 \\
\hline \multicolumn{4}{|l|}{$\begin{array}{rr}\text { gender(reference: } & \text { femal } \\
& \text { e) }\end{array}$} \\
\hline male & $1.298 * * *$ & $1.285 * * *$ & $1.313 * * *$ \\
\hline \multicolumn{4}{|l|}{$\begin{array}{r}\text { College entrance examination } \\
\text { achievement } \\
\text { (reference: } 0 \sim 40 \\
\text { points) }\end{array}$} \\
\hline $41 \sim 80$ points & & $0.908 * * *$ & $0.935 * * *$ \\
\hline $81 \sim 120$ points & & $1.541 * * *$ & $1.544 * * *$ \\
\hline 121 points and more & & $1.894 * * *$ & $1.876 * * *$ \\
\hline \multicolumn{4}{|l|}{ Residence(reference:rural) } \\
\hline urban & & & $0.240 * *$ \\
\hline Cox \& Snell R ${ }^{2}$ & 0.068 & 0.107 & 0.109 \\
\hline Nagelkerke $\mathrm{R}^{2}$ & 0.100 & 0.157 & 0.160 \\
\hline
\end{tabular}

Note: $+\mathrm{p}<0.1, * \mathrm{p}<0.05, * * \mathrm{p}<0.01, * * * \mathrm{p}<0.001$

\section{Conclusions}

This study aimed to explore the effects of individual background and family background on choice of S\&T majors among Chinese high school students. The findings of this research are as follows:

Gender was an important predictor of major choice. Compared to female high school students, male higher school students were more inclined to choose S\&T majors. This finding was similar to those existing literatures. Females were not willing to choose S\&T majors, one explanation may be that they concerned more about the problems in the future, such as the further study, employment, marriage and fertility. In addition, according to some scholars, in some male-dominated professions such as STEM fields, there were obvious gender stereotypes that females were more suitable for the humanities, while males were more suitable for S\&T [26]. 
College entrance examination achievement predicted major choice. College entrance examination achievement was a good predictor of major choice among high school students. Students with high achievement were more inclined to choose S\&T majors when entering university. This conclusion was consistent with previous studies.

Census register had an effect on major choice. Our study showed that census register affected choice of S\&T majors among high school students. Urban students were more inclined to choose S\&T majors than rural students. In China context, census register was an important indicator related to one's family background, so we could believe that family background had a significant impact on high school students' major choice, rich students (urban students) were more inclined to choose S\&T majors than poor students (rural students). This finding was not similar to previous research [27].

The conclusions of the effect of family background on major choice were different among different studies, the main reason may be the influence of the data itself. Further, the influences of family background on major choice were various. When they selected major, students needed to consider many factors such as the risk of academic competition, tuition, returns in the higher education, campus experience. Parents also gave direct effects and there were still some other subtle hidden effects (family atmosphere, power constructing, and environment, etc.). There were differences in social context and culture factors of the research objects of different scholars, so they conclusions may be inconsistent.

\section{Acknowledgement}

This research was supported by a project in the National Natural Science Foundation of China (No.71173168) "The mechanism of gender role, engineering culture, and social change affecting technology orientations to Chinese women engineering students and early engineers", and a project of Soft Science of Shaanxi Province (2015KRM095) "Mechanism of persistence and drop-out of S\&T human resources in Shaanxi Province ".

\section{References}

[1] Sai-jun Tong. Research on the Behavior of Major Selection of Collegial Matriculation, Jiangxi Normal University, 2003. (In Chinese)

[2] J.F.O. Staniec. The Effects of Race, Sex, and Expected Returns on the Choice of College Major, Eastern Economic Journal. 30 (2000) 549-562.

[3] S.W. Polachek. Sex Differences in College Major, Industrial and Labor Relations Review. 31 (1978) 498-508.

[4] E. Blakemore, S.A. Low. Sex Differences in Occupational Selection: The Case of College Majors, The Review of Economics and Statestics. 66 (1984) 157-163.

[5] J.A. Jacobs. Gender and Academic specialties: Trends among recipients of college degrees in the 1980s, Sociology of Education. 68 (1995) 81-98.

[6] J. Roksa. Double Disadvantage or Blessing in Disguise? Understanding the Relationship between College Major and Employment Sector, Sociology of Education. 78 (2005) 207-232.

[7] P. England, S. Li. Desegregation Stalled: The Changing Gender Composition of College Majors, 1971-2002, Gender and Society. 20 (2006) 657-677. 
[8] Yue-lin Fang. The study of difference between social stratification and higher education entrance opportunity, Xiamen University, 1991. (In Chinese)

[9] Cong-bin Guo. Gender difference in the education and employment of science \& engineering students in HEIs, Journal of Higher Education, 11 (2007) 89-101. (In Chinese)

[10] Xin-hong Wang, Xiao-ming Zhang, Rong-rong Zhao. The research of willingness and path for women to choose engineering education in China, Journal of $\mathrm{Xi}$ 'an Jiaotong University (Social Science Edition). 30 (2010) 89-94. (In Chinese)

[11] J.C. Simpson. Segregated by Subject: Racial Differences in the Factors Influencing Academic Major Between European Americans, Asian Americans, and African, Hispanic, and Native Americans, The Journal of Higher Education. 72 (2001) 63-100.

[12] C.Y. Song, J.E. Glick. College Attendance and Choice of College Majors Among Asian-American Students, Social Science Quarterly. 5 (2004) 1401-1421.

[13] N.H. Olitsky. Academic Achievement and the College Major Earnings Differential, University of Massachusetts Dartmouth, 2009.

[14] Yu-nan Yang. The research of the influence factors of college major choice, Liaoning Normal University, 2011. (In Chinese)

[15] Yang-bo Zhang. Social stratification and the unequal education opportunity of rural students - the influence of family economic and social background on rural students' college major choice, Youth Studies. 11 (2002) 20-26. (In Chinese)

[16] Bourdieu, Passeron. Les Heritiers, The Commercial Press, Beijing, 2002. (In Chinese)

[17] Bourdieu, Passeron. La Reproduction, The Commercial Press, Beijing, 2002. (In Chinese)

[18] D. Rochat , J.L. Demeulemeester. Rational choice under unequal constrains: The example of Belgin higher education, Economics of Education Review. 20 (2001) 15-26.

[19] Ying-yi Ma. Family Socioeconomic Status, Parental Involvement, and College Major Choices-Gender, Race/Ethnic, and Nativity Patterns, Sociological Perspective. 52 (2009) 211-234.

[20] Information on http://www.ce.cn/XwZX/kj/201507/17/t20150717_5959489.shtml

[21] ye-zhu Zhao, Lan-ying Qian. The research of college students' behavior of major choice in the 90s, Youth Studies. 4 (1999) 12-15. (In Chinese)

[22] wei-yi Wang, zi-an Gu. The tendency of choosing disciplines in higher institutions and the differences of the access to higher education among the children from strata: based on the explanation of the partiality model, Education \& Economy, 2 (2005) 19-23. (In Chinese)

[23] Fu-dong Dao, Xiao-hao Ding. Family background and college students' major choice, Proceedings of 2008 Annual Meeting of Economics of Education of China, 2008. (In Chinese)

[24] Dong-zhi Cui. A case study on the relations between urban-rural high school students' family background and their intensions of choosing university majors-analyze from the perspective of three-dimensional capital theory, Northeastern Normal University, 2012. (In Chinese) 
[25] Li-jun Yang. The influence of the family socioeconomic status on students' college major choice, Educational Review, 10 (2014) 42-44. (In Chinese)

[26] Ju Tian. A study of gender differences on the choice of discipline or major in higher education - based on the undergraduates' choices on major in central china normal university, Central China Normal University, 2014. (In Chinese)

[27] Mcllwee, Robinson. Women in engineering: gender, power, and workplace culture, State University of New York Press, 1992. 